\title{
Erratum to: Metabolomics of rhabdomyosarcoma cell during echovirus 30 infection
}

\author{
Sarika Tiwari ${ }^{1,2^{*}}$ and Tapan N. Dhole ${ }^{1}$
}

\section{Erratum}

After publication of the article [1], it has been brought to our attention that the $y$-axis labels are missing from the graphs shown in Fig. 7. The missing labels are shown in the corrected graphs below. The original version of the article has been revised to reflect this.

Received: 23 August 2017 Accepted: 24 August 2017

Published online: 19 September 2017

\section{Reference}

1. Tiwari S, Dhole T. Metabolomics of Rhabdomyosarcoma Cell During Echovirus 30 Infection. Virol J. 2017;14:1. doi: 10.1186/s12985-017-0812-7.

\footnotetext{
* Correspondence: sarikatiwari_5@rediffmail.com

'Department of Microbiology (Virology Section), Sanjay Gandhi Post

Graduate Institute of Medical Sciences (SGPGIMS), Uttar Pradesh, Lucknow

-226014, India

${ }^{2}$ Centre for Animal Disease Research and Diagnosis, Indian Veterinary

Research Institute, Bareilly, UP, India
} 

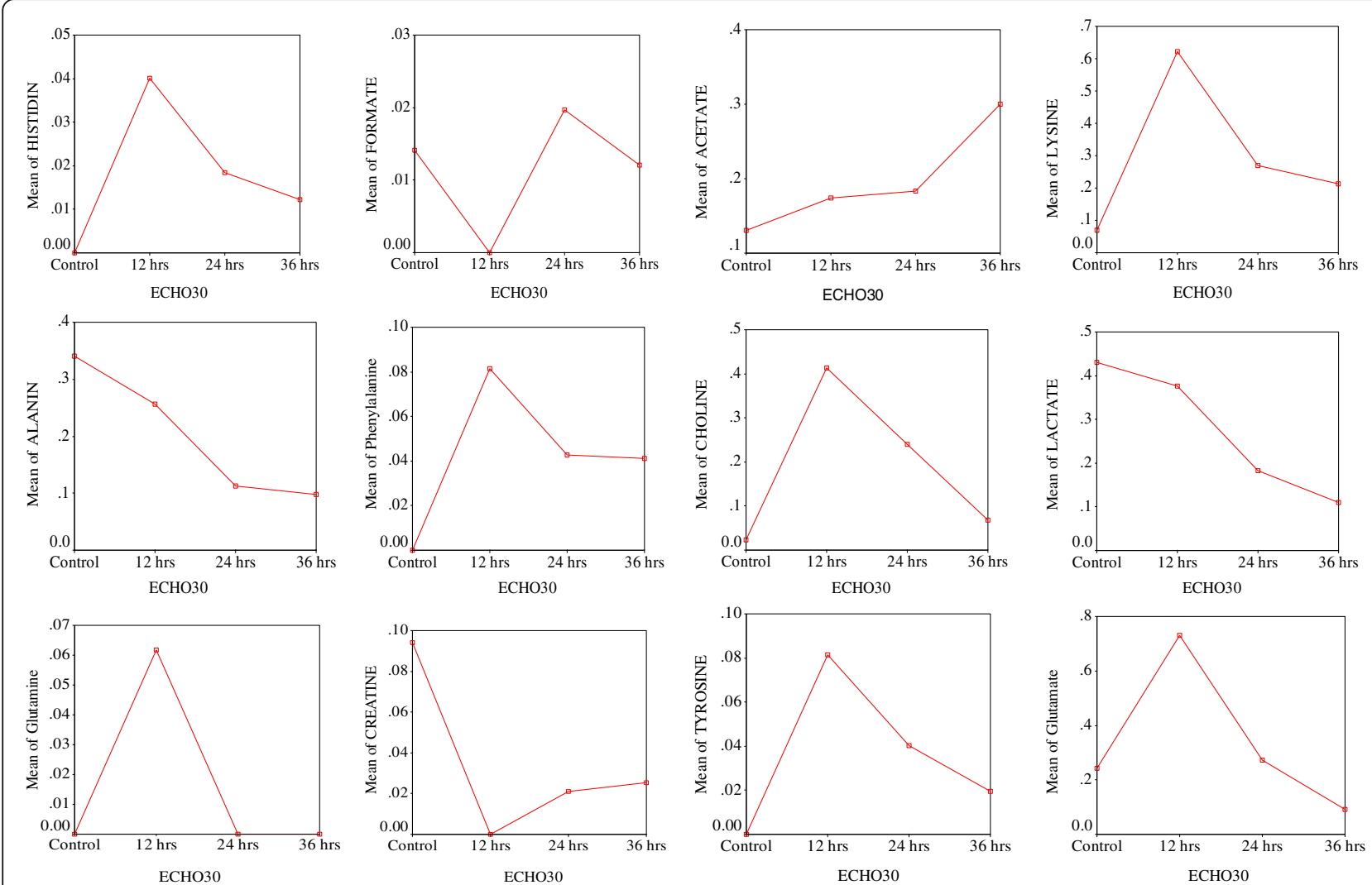

Fig. 7 Time interval showing changes in metabolites after infection in cells 